\title{
The content and size of hyaluronan in biological fluids and tissues
}

\author{
Mary K. Cowman ${ }^{1 *}$, Hong-Gee Lee ${ }^{1}$, Kathryn L. Schwertfeger ${ }^{2}$, James B. McCarthy ${ }^{2}$ and \\ Eva A. Turley ${ }^{3,4,5}$
}

${ }^{1}$ Department of Chemical and Biomolecular Engineering, Biomatrix Research Center, New York University Polytechnic School of Engineering, New York, NY, USA, ${ }^{2}$ Department of Laboratory Medicine and Pathology, Masonic Comprehensive Cancer Center, University of Minnesota, Minneapolis, MN, USA, ${ }^{3}$ Department of Oncology, London Health Sciences Center, Schulich School of Medicine, Western University, London, ON, Canada, ${ }^{4}$ Department of Biochemistry, London Health Sciences Center, Schulich School of Medicine, Western University, London, ON, Canada, ${ }^{5}$ Department of Surgery, London Health Sciences Center, Schulich School of Medicine, Western University, London, ON, Canada

\section{OPEN ACCESS}

Edited by:

David Naor,

Hebrew University of Jerusalem, Israel

Reviewed by:

Feng Gao,

Shanghai Sixth People's Hospital,

China

Shibnath Ghatak,

Medical University of South Carolina,

Robert Stern,

USA

Touro College of Osteopathic

Medicine, USA

Antonio Rosato,

University of Padova, Italy

${ }^{*}$ Correspondence:

Mary K. Cowman,

Biomatrix Research Center, New York

University, 433 First Avenue, New

York, NY 10010 USA

mary.cowman@nyu.edu

Specialty section:

This article was submitted to

Inflammation, a section of the journal

Frontiers in Immunology

Received: 16 February 2015

Accepted: 11 May 2015

Published: 02 June 2015

Citation:

Cowman MK, Lee H-G, Schwertfeger KL, McCarthy JB and Turley EA (2015) The content and size of hyaluronan in biological fluids and

Front. Immunol. 6:261. doi: 10.3389/fimmu.2015.00261
Hyaluronan is a simple repeating disaccharide polymer, synthesized at the cell surface by integral membrane synthases. The repeating sequence is perfectly homogeneous, and is the same in all vertebrate tissues and fluids. The polymer molecular mass is more variable. Most commonly, hyaluronan is synthesized as a high-molecular mass polymer, with an average molecular mass of approximately $1000-8000 \mathrm{kDa}$. There are a number of studies showing increased hyaluronan content, but reduced average molecular mass with a broader range of sizes present, in tissues or fluids when inflammatory or tissue-remodeling processes occur. In parallel studies, exogenous hyaluronan fragments of low-molecular mass (generally, $<200 \mathrm{kDa}$ ) have been shown to affect cell behavior through binding to receptor proteins such as CD44 and RHAMM (gene name HMMR), and to signal either directly or indirectly through toll-like receptors. These data suggest that receptor sensitivity to hyaluronan size provides a biosensor of the state of the microenvironment surrounding the cell. Sensitive methods for isolation and characterization of hyaluronan and its fragments have been developed and continue to improve. This review provides an overview of the methods and our current state of knowledge of hyaluronan content and size distribution in biological fluids and tissues.

Keywords: hyaluronan, quantification, assay, molecular mass, molecular weight

\section{Introduction}

Hyaluronan (hyaluronic acid, HA) is found in vertebrate tissues, as a key component of the extracellular matrix. It has a simple covalent structure consisting of alternating $\beta$-D-glucuronate and $N$-acetyl- $\beta$-D-glucosamine sugars. The linear anionic polymer has a semi-flexible structure, causing it to adopt an expanded wormlike random coil. The domain of a coiled chain can be conceptually described as a sphere [mostly filled with (unbound) solvent], with a dynamically changing chain configuration. The apparent volume occupied by a single isolated molecule depends strongly on the chain length, and thus the molecular mass, $M$. The volume increases approximately as $M$ raised to the 1.8 power, as dictated by polymer chain statistics (1). Where HA chains are crowded together, their domains are forced to interpenetrate, and this leads to severe nonideality in behavior. The non-ideality determines such properties as the large colloid osmotic pressure, viscoelasticity, and effect on partition of other macromolecules (excluded volume) in the biomatrix. Since the molecular mass of HA in normal biological fluids and tissues is normally 
very high (ca. 1000-8000 kDa), the non-ideality effects dominate the physicochemical properties of $\mathrm{HA}$ in the extracellular matrix (2-4).

In addition to the physicochemical effects due to mutual macromolecular crowding, HA has important binding interactions. At the cell surface, HA provides a protective coat that is tethered to receptors embedded in the cell membrane (5-7). Beyond the cell surface, HA organizes proteoglycans (e.g., versican, aggrecan) and other binding proteins via specific non-covalent interactions, creating a further highly hydrated and charged domain (8-10). In inflammation and other specific tissue-remodeling processes, covalent transfer of the heavy chain domains of $I \alpha I$ to HA can be catalyzed by TSG-6 protein (11-14). The HAprotein assemblies, whether covalently or non-covalently mediated, are integral to maintenance of an expanded pericellular matrix.

Normally, HA has a high turnover rate $(15,16)$. Thus, the extracellular environment is constantly renewed. The need for renewal may reside in the protective role HA fulfills. Facile degradation of HA by reactive oxygen and nitrogen species (ROS/RNS) (17, 18) during active inflammation can weaken the protective HA coat that usually protects the cell. The HA acts as a scavenger of damaging free radicals and other chemical agents. If the rate of HA synthesis keeps pace with the rate of degradation and turnover, the homeostatic environment is maintained (19).

When the rate of HA degradation is not adequately compensated by its synthesis, fragments of the polymer might be present at significant levels and consequently cells are poorly protected. Changes in the physicochemical control of the pericellular environment take place. HA fragments compete in binding interactions with proteins, altering the integrity of the biomatrix. Fragments can displace high $M$ HA in interactions with cell surface receptors, resulting in changes in receptor clustering and altered signaling (20). Fragments can also signal through alternate receptors (21-23). In these ways, HA may be regarded as a biosensor of damaging processes in the cellular microenvironment. Altering the balance of high and low $M \mathrm{HA}$ is a stimulus that sets in motion multiple cellular response mechanisms. These can be purely defensive, such as HA fragment-induced expression of $\beta$-defensins to combat microbial infection in the gut $(24,25)$. But sustained responses can also lead to chronic inflammation via aberrant signaling through receptors and consequently increased expression of inflammation mediators (26).

Tissue-remodeling processes, including wound healing and tumor progression, are associated with changes in HA content and size (27-31). HA synthesis is usually increased during remodeling, but increased expression of hyaluronidases may also occur, and together with macrophage-generated ROS/RNS, degrade HA. The balance of high and low M HA may differ from the homeostatic case, thus altering both the physicochemical and signaling effects of HA. To understand HA biology, we are faced with multiple questions: (1) What is the content of HA present, (2) What is the molecular mass distribution of the HA, and (3) Can we control pathological processes by altering the content, size, and binding interactions of $\mathrm{HA}$ ?

\section{Isolation of HA}

There are a number of methods appropriate for assaying the content and size of HA in biological fluids and tissues. Depending on the method, it may be necessary to purify HA to remove/digest bound proteins and sulfated glycosaminoglycans prior to assay.

The isolation of HA follows protocols $(25,30,32-35)$ that are quite similar to those historically employed in the purification of DNA. The requirement for specific steps depends on the nature of the sample: fluid tissue vs. conditioned medium from cell culture vs. solid tissue. For solid tissues, the HA is extracted into soluble form, and liberated from proteins. Protein removal can be accomplished by digestion with a protease, or by denaturing the protein by gentle mixing with chloroform. Lipids are removed with acetone or other organic solvent mixtures. Removal of lowmolecular mass contaminants may require dialysis, or precipitation of the HA with ethanol or isopropyl alcohol. DNA and RNA can be enzymatically digested. There are many variations on these steps. A sample protocol for extraction of HA from solid tissue might include the following steps: digestion with a protease such as proteinase $\mathrm{K}$, boiling to denature enzyme, centrifugation, extraction with chloroform, centrifugation, dialysis, precipitation with ethanol, centrifugation, re-dissolution, digestion with Benzonase (or DNase plus RNase), boiling to denature enzyme, and repeat of steps starting with chloroform extraction. Abbreviated protocols can be used for fluid samples, or where the HA needs to be liberated but not purified because specific assay will be employed.

The above purification will not remove other glycosaminoglycans. Sulfated glycosaminoglycans can be removed by anion exchange chromatography. Unsulfated or undersulfated chondroitin, which is rare in normal tissues but may be significant in remodeling tissues, is not removed by this process. At this point in the procedure, specific isolation of HA can be accomplished by affinity methods, such as use of a biotinylated HA-specific binding protein and streptavidin-coated magnetic beads, or other similar medium such as gel beads $(36,37)$.

It is worth noting that most isolation methods in current use have not been validated with respect to quantitative yield of $\mathrm{HA}$, or preferential extraction/isolation of specific HA sizes. In particular, losses of very low $M$ HA may be significant in some procedures. It is also possible to degrade HA during isolation. Endogenous enzymes may cause some of this degradation. However, most degradation is the result of ROS generation catalyzed by contaminating iron (II) or copper (I), and molecular species that regenerate the active metal ion oxidation states. Thus, use of papain activated with cysteine can lead to HA degradation (38). The presence of EDTA can also enhance the ability of contaminating iron to catalyze formation of hydroxyl radicals. Iron contamination is better inactivated by chelation with deferoxamine (34). Also, of note, EDTA and phosphates can be co-precipitated with HA using ethanol.

Testing for degradation of HA during isolation can be easily accomplished by "spiking" the initial fluid or tissue with a pure HA sample of known $M$ and low polydispersity in $M$, and then testing its size in the final isolate. Spiking samples with known amounts of HA can also be used to detect losses during isolation, 
including losses due to non-specific interactions with surfaces or other macromolecules that HA may not normally contact.

\section{Methods to Analyze Content of HA}

The most simple and historical assay for HA is measurement of uronic acid content. The assay involves hydrolysis in concentrated sulfuric acid, so that protein content is not a problem. Other glycosaminoglycans that contain uronic acid will contribute to the result, and should be separated or removed from HA if possible. The uronic acid assay has been widely employed, especially in analysis of fluids (synovial fluid, vitreous) with high HA and low sulfated glycosaminoglycan content.

Hyaluronic acid content can be also determined by analysis of the oligosaccharide products of enzymatic digestion. Quantification is accomplished by methods such as HPLC, capillary electrophoresis (CE), mass spectrometry, or fluorophore-assisted carbohydrate electrophoresis. These methods have primarily been employed to determine relative amounts of different glycosaminoglycans in a sample, rather than absolute quantities.

The most sensitive, specific, and accurate methods for determination of HA content are based on enzyme-linked sorbent assays (ELSA, ELISA-like assays) (39-47). The specific detection of HA is an important step of these methods, because purification of low $M \mathrm{HA}$ is difficult, and contaminants interfere with non-specific detection modes. The specificity is based on the use of molecular species such as proteins or proteoglycans that recognize and bind HA but no other biological molecules. For example, the aggrecan proteoglycan binds HA specifically $(8,9)$. The intact proteoglycan may be used, or a terminal fragment called globular domain 1 interglobular domain - globular domain 2 (G1-IGD-G2), often referred to as HA-binding protein (HABP) or HA-binding region (HABR). The link protein, also called CRTL1 or HAPLN1, is similar to the G1 domain of aggrecan, and is another suitable protein for specific detection of HA. Isolated HABP, usually a mixture of the aggrecan HABR and the link protein, may also be used. Similarly, versican proteoglycan G1 domain is useful. Hyaluronectin, a HA-specific binding protein isolated from brain, may be used. Recently, a recombinant fusion protein of human TSG- 6 and the Fc domain of human IgG, and a second variant of the fusion protein in which the heparin-binding region of TSG6 was mutated to become inactive, were found to be suitable for development of a specific HA assay (47). Other HA-specific binding molecules could be used.

There are two types of ELSA. The first type, sandwich assays, are sensitive and reproducible, but fail to adequately quantify low $M$ HA (39-42). This is because the plate surface, coated with an HABP, strongly binds HA, but does not allow further probing of short HA chains by the detector protein (43). Longer HA chains have accessibility as a result of looped sections above the surface. (The same problem occurs in HA blotted to positively charged nylon membranes after electrophoresis, from which short HA chains cannot be detected.) The second type of ELSA is competitive assays. In these, HA is usually immobilized on a surface such as the wells of a plastic 96-well plate. Alternative surfaces are suitably modified magnetic beads. Soluble HA samples, either standards or unknowns, are mixed with the specific binding agent, usually a protein or proteoglycan. The soluble HA competes with immobilized surface HA for the specific binding agent, so that the resulting surface-bound amount of the binding agent is a measure of the amount of soluble HA in the sample being analyzed (41, 44, 45). There are multiple possible detection schemes to quantify the bound agent. For example, if aggrecan proteoglycan is the specific binding agent, it can be quantified with an antibody to the keratan sulfate chains of aggrecan, and a suitably labeled second antibody. When the specific binding agent is a labeled (e.g., biotinylated) HABP, it can be quantified by binding of the label to a specific agent such as streptavidin, which is, in turn, conjugated to an enzyme or other detectable species. Radiolabeled HABP may also be used but is less desirable on the basis of safety and disposal. Because the recognition step in a competitive binding assay occurs in solution, HA chains as short as approximately decasaccharides can be accurately detected, depending on the labeled binding protein used. The results of sandwich and competitive assays have been shown to be in good agreement for high $M$ HA (46).

\section{HA Content in Biological Fluids and Tissues}

The content of HA in many normal biological fluids has been determined. Here, we cite a few relevant results. HA is a major component of articular joint synovial fluid, where it provides the viscoelasticity and lubrication necessary for protection of cartilage surfaces. Its concentration in the human knee joint is approximately $2-3 \mathrm{mg} / \mathrm{ml}$, being slightly higher in younger adults than in older adults (48-50). HA is also a major component of the vitreous body of the eye, but at a lower concentration of approximately $200 \mu \mathrm{g} / \mathrm{ml}$, in the phakic human eye vitreous (51). The concentration in the aqueous humor is lower still, being only about $1 \mu \mathrm{g} / \mathrm{ml}$ (52). Human lymph fluid contains $\mathrm{HA}$ at a concentration of about $0.1-18 \mu \mathrm{g} / \mathrm{ml}$ (36). In the blood serum of healthy human adults, the concentration of HA is lower still, being usually between 10 and $100 \mathrm{ng} / \mathrm{ml}$, mostly $20-40 \mathrm{ng} / \mathrm{ml}$, and averaging about $30 \mathrm{ng} / \mathrm{ml}$ $(36,40,44)$. Normal human urine also contains a low level of HA, around $100-300 \mathrm{ng} / \mathrm{ml}(44)$, and human milk similarly contains $\mathrm{HA}$ at about $200-800 \mathrm{ng} / \mathrm{ml}$ (25).

The HA content of solid tissues varies widely. Bovine nasal cartilage contains approximately $1200 \mu \mathrm{g} \mathrm{HA} / \mathrm{g}$ wet tissue weight (44). The HA content of human articular cartilage is similar, being about $500-2500 \mu \mathrm{g} / \mathrm{g}$ (53). Human skin contains approximately 400-500 $\mu \mathrm{g} \mathrm{HA} / \mathrm{g}$ tissue, mostly in the dermis (54). Fetal skin and young skin have higher HA contents than older skin. Other organs have much less HA. Laurent and Tengblad (44) reported HA contents of approximately $1-100 \mu \mathrm{g} \mathrm{HA} / \mathrm{g}$ wet tissue weight for most organs. Rabbit kidney had $103 \mu \mathrm{g} / \mathrm{g}$, brain had $65 \mu \mathrm{g} / \mathrm{g}$, muscle had $27 \mu \mathrm{g} / \mathrm{g}$, liver had $1.5 \mu \mathrm{g} / \mathrm{g}$, and cornea had $1.3 \mu \mathrm{g} / \mathrm{g}$. Armstrong and Bell (34) also reported rabbit tissue HA contents of $500 \mu \mathrm{g} / \mathrm{g}$ for skin, $200 \mu \mathrm{g} / \mathrm{g}$ for large intestine and heart, $130 \mu \mathrm{g} / \mathrm{g}$ for small intestine, and $80-90 \mu \mathrm{g} / \mathrm{g}$ for lung and muscle tissues.

Measurement of HA content is of continuing high interest, because there are multiple studies correlating changes in HA content with tissue remodeling and pathological processes. While the normal HA concentration in human serum is usually $<40 \mathrm{ng} / \mathrm{ml}$, it is elevated $(>46.5 \mathrm{ng} / \mathrm{ml})$ in hepatic cirrhosis (55), in rheumatoid arthritis $(56,57)$ (highly variable; reports up to nearly $200 \mu \mathrm{g} / \mathrm{ml}$, 
but more generally between 0.07 and $6.4 \mu \mathrm{g} / \mathrm{ml}$ ), in ankylosing spondylitis $(57)(7-13 \mu \mathrm{g} / \mathrm{ml})$, and in osteoarthritis $(57,58)$ $(0.04-2.3 \mu \mathrm{g} / \mathrm{ml})$. The elevated HA concentration in serum of patients with hepatic cirrhosis is utilized as one component of a diagnostic assay. A small but significant elevation (frequently, about twofold) of HA in serum is found in multiple types of untreated cancer (59-61). Radical surgery to remove the tumor causes the HA concentration in serum to return to the normal range. Most interestingly, it was found that the low-molecular mass component of serum $\mathrm{HA}$ can be used to differentiate metastatic from non-metastatic breast cancer (62), which may form the basis of a new diagnostic test.

In solid tissues, many but not all cancers progress in a tumor microenvironment of increased HA content (28). Further, some non-aggressive cancer types such as non-malignant fibroadenoma produce elevated HA $(63,64)$. The presence of HA may therefore not be sufficient by itself to promote tumorigenesis. However, high levels of HA accumulate in lung, colorectal, prostate, bladder, and breast carcinomas and in these cancers are linked to tumor aggression (28). For example, the HA content of human lung tissue increases 4- to 200-fold in lung carcinoma (65), 100-fold in grade 3 ovarian cancer (66) and 7-fold in prostate cancer (67). Increased tumor HA accumulation is also linked to tumor aggression. The HA content of malignant ovarian epithelial tumor correlates with tumor grade and with metastasis. Elevated HA accumulation within the stroma or tumor parenchyma of breast cancer is associated with unfavorable prognosis of the patient. Recent studies have further linked high stromal HA staining to HER2 positive tumors and poor outcome parameters including time to relapse, large tumor size, lymph node positivity, hormone receptor negativity, high body mass, and shortened overall survival (68). Elevated $\mathrm{HA}$ in the tumor microenvironment is linked to inflammation (69). Thus, high amounts of both tumor-associated macrophages and $\mathrm{HA}$ are concurrent in breast carcinoma. High macrophage numbers correlate with high tumor HA, HAS expression and poor outcome, suggesting that HA facilitates a macrophage tumor supporting function in breast cancer. The link between inflammation and cancer has led to recent interest in HA as a contributor to a pro-tumorigenic inflammatory environment, as detailed in a companion article in this issue (70).

As for cancer, wound healing and fibrosis are associated with inflammation and increased HA content (71). An approximately twofold increase was observed in HA content of rat skin during healing of excisional wounds (30). Similarly, scleroderma patients with early stage disease have an approximately twofold increase in serum HA (72). Many other pathological states characterized by inflammation similarly have elevated HA, as estimated by immunohistochemical analyses $(73,74)$.

\section{Methods to Analyze HA Molecular Mass Distribution}

It has long been appreciated that degradation of HA negatively affects its biomechanical properties. For example, degradation of $\mathrm{HA}$ in articular joint synovial fluid can reduce the viscosity and elasticity of the synovial fluid, and has also been shown to reduce its lubricating ability $(49,75)$. The widespread and successful uses of solutions of high molecular mass HA as a viscosurgical tool in ophthalmic surgery, and as an analgesic treatment for osteoarthritis, are based on this understanding. More recently, the discovery that exogenous HA fragments can alter cellular behavior by signaling through multiple receptor proteins, and that the existence of such fragments in vivo is likely, based on increased hyaluronidase levels and reactive oxygen and nitrogen species in tissue remodeling and pathological processes, has led to increased interest in measuring the size distribution of HA in biological fluids and tissues.

Many current methods for determination of the $M$ distribution of HA from tissues and biological fluids have been optimized for highly purified HA. A commonly employed method used commercially is size exclusion chromatography with multiangle laser light scattering (SEC-MALLS) $(76,77)$. However, detection of very low $M$ HA by light scattering is inherently insensitive, and the SEC-MALLS method requires a highly purified HA sample. CE (78) is similarly limited to pure HA samples. MALDI-TOF mass spectrometry $(79,80)$ has high sensitivity, but requires a pure sample and HA with $M$ larger than about $10 \mathrm{kDa}$ becomes difficult to analyze. A new method that has extremely high sensitivity and works best for low $M \mathrm{HA}$ is gas-phase electrophoretic mobility molecular analysis (GEMMA), but it still requires pure HA (81).

The most widely used methods, to date, for size distribution analysis of imperfectly pure HA isolated from biological samples are size exclusion chromatography with enzyme-linked sorbent assay (SEC-ELSA) $(36,56,82)$, and agarose or polyacrylamide gel electrophoresis (83-86) with staining or with blotting and specific detection. Both methods are capable of detecting a wide range of HA sizes. Gel electrophoresis with staining can analyze samples on the microgram scale, and can tolerate some impurities in the sample, but non-specific staining by those impurities can interfere with size distribution analysis of the HA. Blotting of gels to positively charged nylon and detection of HA using a labeled specific binding protein works only for HA with $M>100 \mathrm{kDa}$, as a result of strong surface binding (43). To address the issues of limited sample amount, purification difficulty, and the importance of analyzing both high and low $M$ HA simultaneously, we recently developed a method using size-dependent fractionation of HA by anion exchange on a spin column, and quantification of HA in the fractions using a competitive ELSA assay (IEX-ELSA) (37). All of these methods require calibration with purified HA samples of known size.

\section{HA Size in Biological Fluids and Tissues}

The average $M$ and distribution of $M$ for HA present in biological sources have been studied primarily for fluid tissues such as synovial fluid, vitreous, serum, lymph, and milk. Until recently, the emphasis has been on documenting reduction of the average $M$, which strongly affects the biomechanical properties of HA solutions (48, 87-89). This has been done using physicochemical methods such as viscometry, light scattering, and sedimentation-diffusion. Interest in the distribution of sizes present, and the possibility that specific sizes have unique biological effects, has led to an increasing number of studies by chromatographic and electrophoretic separation methods. 


\section{SYNOVIAL FLUID HYALURONAN}

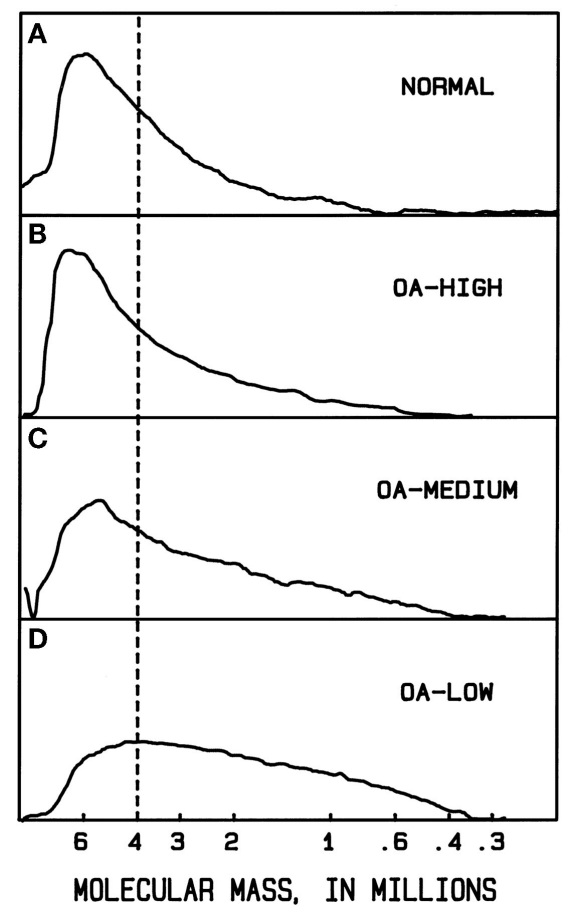

FIGURE 1 | Example molecular mass distributions of human synovial fluid (SF) HA determined by agarose gel electrophoresis. From top to bottom: (A) normal human SF obtained from young healthy volunteers. (B-D) Representative osteoarthritis (OA) patient SF. The dashed vertical line corresponds to the migration position of $4000 \mathrm{kDa} \mathrm{HA}$. The fraction of $\mathrm{HA}$ having slower electrophoretic migration, and thus higher $M$ than $4000 \mathrm{kDa}$, is a measure of the high $M \mathrm{HA}$ content. In normal human SF, the portion of HA with $M>4000 \mathrm{kDa}$ averaged $61 \%$. OA patients varied in the extent of $\mathrm{HA}$ degradation. The OA-HIGH profile, similar to that seen in normal SF and representative of OA samples with more than $60 \%$ of $\mathrm{HA}$ having $M>4000 \mathrm{kDa}$, was found for $26 \%$ of patients. The OA-MEDIUM profile, representative of OA samples with approximately $41-60 \%$ of $\mathrm{HA}$ having $M>4000 \mathrm{kDa}$, was found for $41 \%$ of patients. The OA-LOW profile, representative of OA samples with $<40 \%$ of $\mathrm{HA}$ having $M>4000 \mathrm{kDa}$, was found for $33 \%$ of patients. From Lee (90).

In normal human synovial fluid, most of the HA is very high in molecular mass. Gel filtration chromatography with HA-specific detection (50) and agarose gel electrophoresis with staining (84, 90) show the average $M$ to be approximately $6000-7000 \mathrm{kDa}$, with little if any $\mathrm{HA}<1000 \mathrm{kDa}$. In rheumatoid arthritis and in osteoarthritis, HA can be partially degraded, resulting in a broad distribution of sizes, extending perhaps down to a few hundred kilodaltons $(90,91)$ (Figure 1). Normal rabbit vitreous HA has mostly high $M(2000-3000 \mathrm{kDa})$, but bovine vitreous HA has mostly moderate $M(500-800 \mathrm{kDa})$ (82). Owl monkey vitreous has very high $M \mathrm{HA}$ (84).

For fluids containing HA at very low concentrations, determination of the $M$ distribution is correspondingly difficult. Despite this, evidence for the occurrence of HA below $100 \mathrm{kDa} \quad(<250$ disaccharides) in $M$ is accumulating. Human milk contains mainly HA with an average $M$ of about $440 \mathrm{kDa}$, and also has been definitively shown to have approximately $5 \%$ of HA with $M<100 \mathrm{kDa}$ (37). The low $M \mathrm{HA}$ is proposed to participate in stimulating the expression of human $\beta$-defensin 2 in the infant intestinal epithelium (24). Human amniotic fluid contains HA with an average $M$ of about $330 \mathrm{kDa}$ at 16 weeks gestation, but the $M$ distribution changes to a mixture of high and very low $M$ HA by 40 weeks gestation (92). HA in lymph fluid is variable in size, and can occur as a mixture of high and lower $M$ components (36), or as a broad distribution of moderate $M$, ca. $800 \mathrm{kDa}$ average (93). HA in normal blood serum is mainly relatively low $M$ (ca. $100-300 \mathrm{kDa})(36,56)$. It is also low in $M$ in saliva and urine $(94,95)$.

Tumors have been proposed to shed very low $M$ HA into associated body fluids. The quantity of such very low (but undetermined size) $M \mathrm{HA}$ in patient serum, obtained by centrifugal filtration, has been reported to be associated with metastatic breast cancer (62). It has also been reported in saliva of patients with head and neck tumors (95), and in the urine of patients with bladder cancers (94). The precise size of all such HA has not yet been determined, but should be accessible using recent improvements in methods. Rarely, high $M$ HA is found in serum, as, for example, associated with Wilm's tumor (96).

For solid tissues, the pattern is a bit simpler. Normal healthy tissues are almost always associated with high $M$ HA. HA with average $M>2000 \mathrm{kDa}$ is found in young human cartilage (53). Larger HA averaging closer to $4000-6000 \mathrm{kDa}$ is found in human skin (54), in rabbit skin (34), and in rat skin (30, 97). High $M$ HA is found in rooster combs (32). High $M$ HA is also found in skeletal muscle, lung, heart, ileum, and colon of the rabbit (34). Little if any low $M$ HA is found in these healthy tissues.

Remodeling tissues and tumors show evidence of some lower $M$ HA. Reduction in HA $M$ occurs in older human cartilage (53). Low $M$ HA also occurs in healing rat skin wounds (30), in human skin following irradiation with UVB (74), and in mouse cervix undergoing postpartum remodeling (98). It is found in rat kidney after ischemia-reperfusion injury (99). Human prostate tumor HA has also been reported to contain some low $M$ HA of indeterminate size (67). Many of the above-described studies of reduced $M$ HA should be regarded as indicative but not conclusive proof of the presence of specific low $M$ HA species. Recent improvements in techniques for analysis of very low quantities of polydisperse HA will allow this uncertainty to be addressed. Future studies should also include spiking samples with multiple monodisperse HA species to show that the isolation methods cause no degradation, or preferential isolation of high or low $M$ HA.

It is interesting to consider that all efforts to determine the content and size of HA in biological tissues and fluids have made the tacit assumption that the HA has a constant chemical structure, except for variation in size. Since degradation by ROS/RNS can cause chemical changes including ring opening reactions, it is possible that HA assays and size analyses may be influenced by such changes, if present at significant levels. Further examination of this possibility is warranted.

\section{Conclusion}

It is now well established that HA synthesis is significantly increased in remodeling tissues and tumors. The concomitant 
presence of hyaluronidases and ROS/RNS makes it likely that fragments of HA can be created by degradation of high $M$ polymers. The balance of synthetic and degradative activities, coupled with turnover through outflow or internalization, will determine the steady state $M$ distribution of the tissue HA. HA shed into lymph or blood from a tumor may represent only the lowest $M$ fraction of that present. Whether HA fragments of particular sizes exist in sufficient amounts within a tissue or tumor environment to trigger specific cellular responses is not yet clear. The fact that exogenous HA fragments can elicit such effects is suggestive but not yet a proof of their role in vivo. There is good reason to expect clarity on these issues in the near future.

\section{References}

1. Cowman MK, Matsuoka S. The intrinsic viscosity of hyaluronan. In: Kennedy JF, Phillips GO, Williams PA, editors. Hyaluronan. Cambridge: Woodhead Publishing (2002). p. 75-8.

2. Laurent TC. An early look at macromolecular crowding. Biophys Chem (1995) 57:7-14. doi:10.1016/0301-4622(95)00048-3

3. Cowman MK, Matsuoka S. Experimental approaches to hyaluronan structure. Carbohydr Res (2005) 340:791-809. doi:10.1016/j.carres.2005.01.022

4. Cowman MK, Hernandez M, Kim JR, Yuan H, Hu Y. Macromolecular crowding in the biomatrix. In: Balazs EA, editor. Structure and Function of Biomatrix: Control of Cell Behavior and Gene Expression. Edgewater, NJ: Matrix Biology Institute (2012). p. 45-66.

5. Toole BP. Hyaluronan: from extracellular glue to pericellular cue. Nat Rev Cancer (2004) 4:528-39. doi:10.1038/nrc1391

6. Evanko SP, Tammi MI, Tammi RH, Wight TN. Hyaluronan-dependent pericellular matrix. Adv Drug Deliv Rev (2007) 59:1351-65. doi:10.1016/j.addr.2007. 08.008

7. Itano N. Simple primary structure, complex turnover regulation and multiple roles of hyaluronan. J Biochem (2008) 144:131-7. doi:10.1093/jb/mvn046

8. Hascall VC, Heinegård D. Aggregation of cartilage proteins. I. The role of hyaluronic acid. J Biol Chem (1974) 249:4232-41.

9. Bonnet F, Dunham DG, Hardingham TE. Structure and interactions of cartilage proteoglycan binding region and link protein. Biochem J (1985) 228:77-85.

10. Mörgelin M, Paulsson M, Hardingham TE, Heinegård D, Engel J. Cartilage proteoglycans. Assembly with hyaluronate and link protein as studied by electron microscopy. Biochem J (1988) 253:175-85.

11. Yingsung W, Zhuo L, Morgelin M, Yoneda M, Kida D, Watanabe H, et al. Molecular heterogeneity of the SHAP-hyaluronan complex. Isolation and characterization of the complex in synovial fluid from patients with rheumatoid arthritis. J Biol Chem (2003) 278:32710-8. doi:10.1074/jbc.M303658200

12. Day AJ, de la Motte CA. Hyaluronan cross-linking: a protective mechanism in inflammation? Trends Immunol (2005) 26:637-43. doi:10.1016/j.it. 2005.09.009

13. Colón E, Shytuhina A, Cowman MK, Band PA, Sanggaard K, Enghild JJ, et al. Transfer of inter- $\alpha$-inhibitor heavy chains to hyaluronan by surface-linked hyaluronan - TSG-6 complexes. J Biol Chem (2009) 284:2320-31. doi:10.1074/ jbc.M807183200

14. He H, Li W, Tseng DY, Zhang S, Chen SY, Day AJ, et al. Biochemical characterization and function of complexes formed by hyaluronan and the heavy chains of inter-alpha-inhibitor ( $\mathrm{HC}^{\star} \mathrm{HA}$ ) purified from extracts of human amniotic membrane. J Biol Chem (2009) 284:20136-46. doi:10.1074/jbc.M109.021881

15. Laurent TC, Laurent UBG, Fraser JR. The structure and function of hyaluronan: an overview. Immunol Cell Biol (1996) 74:A1-7. doi:10.1038/icb.1996.32

16. Fraser JRE, Laurent TC, Laurent UBG. Hyaluronan: its nature, distribution, functions and turnover. J Intern Med (1997) 242:27-33. doi:10.1046/j. 1365-2796.1997.00170.x

17. Li M, Rosenfeld L, Vilar RE, Cowman MK. Degradation of hyaluronan by peroxynitrite. Arch Biochem Biophys (1997) 341:245-50. doi:10.1006/abbi. 1997.9970

18. Šoltés L, Kogan G. Impact of transition metals in the free-radical degradation of hyaluronan biopolymer. In: Pearce E, Zaikov GE, Kirschenbaum G, editors.

\section{Author Contributions}

MC, HL, KS, JM, and ET contributed to the drafting and revising of this manuscript. All authors approved this manuscript.

\section{Acknowledgments}

This work was supported in part by The Endre A. Balazs Foundation (MC), the Fund for Neurodegeneration and Inflammation at New York University (MC), NIH R01 CA132827 (KS), Chairman's Fund Professor in Cancer Research (JM), and the Prostate Cancer Society of Canada (ET).

Kinetics and Thermodynamics for Chemistry and Biochemistry. Hauppauge, NY: Nova Science (2009). p. 181-99.

19. Tammi MI, Day AJ, Turley EA. Hyaluronan and homeostasis: a balancing act. J Biol Chem (2002) 277:4581-4. doi:10.1074/jbc.R100037200

20. Yang C, Cao M, Liu H, He Y, Xu J, Du Y, et al. The high and low molecular weight forms of hyaluronan have distinct effects on CD44 clustering. J Biol Chem (2012) 287:43094-107. doi:10.1074/jbc.M112.349209

21. Noble PW, McKee CM, Cowman M, Shin HS. Hyaluronan fragments activate an NF- $\kappa \mathrm{B} / \mathrm{I}-\kappa \mathrm{B} \alpha$ autoregulatory loop in murine macrophages. $J$ Exp Med (1996) 183:2373-8. doi:10.1084/jem.183.5.2373

22. McKee CM, Penno MB, Cowman M, Bao C, Noble PW. Hyaluronan (HA) fragments induce chemokine gene expression in murine alveolar macrophages. The role of HA size and CD44. J Clin Invest (1996) 98:2403-13. doi:10.1172/ JCI119054

23. Jiang D, Liang J, Noble PW. Hyaluronan as an immune regulator in human diseases. Physiol Rev (2011) 91:221-64. doi:10.1152/physrev.00052.2009

24. Hill DR, Kessler SP, Rho HK, Cowman MK, de la Motte CA. Specific-sized hyaluronan fragments promote expression of human $\beta$-defensin 2 in intestinal epithelium. J Biol Chem (2012) 287:30610-24. doi:10.1074/jbc.M112.356238

25. Hill DR, Rho HK, Kessler SP, Amin R, Homer CR, McDonald C, et al. Human milk hyaluronan enhances innate defense of the intestinal epithelium. J Biol Chem (2013) 288:29090-104. doi:10.1074/jbc.M113.468629

26. Stern R, Asari AA, Sugahara KN. Hyaluronan fragments: an information-rich system. Eur J Cell Biol (2006) 85:699-715. doi:10.1016/j.ejcb.2006.05.009

27. Toole BP, Wight TN, Tammi MI. Hyaluronan-cell interactions in cancer and vascular disease. J Biol Chem (2002) 277:4593-6. doi:10.1074/jbc.R100039200

28. Tammi RH, Kultti A, Kosma V-M, Pirinen R, Auvinen P, Tammi MI. Hyaluronan in human tumors: pathobiological and prognostic messages from cellassociated and stromal hyaluronan. Semin Cancer Biol (2008) 18:288-95. doi:10. 1016/j.semcancer.2008.03.005

29. Itano N, Zhuo L, Kimata K. Impact of the hyaluronan-rich tumor microenvironment on cancer initiation and progression. Cancer Sci (2008) 99:1720-5 doi:10.1111/j.1349-7006.2008.00885.x

30. Tolg C, Zalinska E, Hamilton S, McCulloch L, Akentieva N, Winnik F, et al. A RHAMM mimetic peptide blocks hyaluronan fragment signaling and promotes skin excisional wound repair by reducing inflammation. Am J Pathol (2012) 181:1250-70. doi:10.1016/j.ajpath.2012.06.036

31. Tolg C, McCarthy JB, Yazdani A, Turley EA. Hyaluronan and RHAMM in wound repair and the "cancerization" of stromal tissues. Biomed Res Int (2014) 2014:103923. doi:10.1155/2014/103923

32. Balazs EA. Ultrapure Hyaluronic Acid and the Use Thereof. (1979) US Patent $4,141,973$.

33. Itano N, Sawai T, Yoshida M, Lenas P, Yamada Y, Imagawa M, et al. Three isoforms of mammalian hyaluronan synthases have distinct enzymatic properties. J Biol Chem (1999) 274:25085-92. doi:10.1074/jbc.274.35.25085

34. Armstrong SE, Bell DR. Measurement of high-molecular-weight hyaluronan in solid tissue using agarose gel electrophoresis. Anal Biochem (2002) 308:255-64 doi:10.1016/S0003-2697(02)00239-7

35. Lauer ME, Mukhopadhyay D, Fulop C, de la Motte CA, Majors AK, Hascall VC. Primary murine airway smooth muscle cells exposed to poly $(\mathrm{I}, \mathrm{C})$ or tunicamycin synthesize a leukocyte-adhesive hyaluronan matrix. J Biol Chem (2009) 284:5299-312. doi:10.1074/jbc.M807965200 
36. Tengblad A, Laurent UBG, Lilja K, Cahill RNP, Engström-Laurent A, Fraser JRE, et al. Concentration and relative molecular mass of hyaluronate in lymph and blood. Biochem J (1986) 236:521-5.

37. Yuan H, Amin R, Ye X, de la Motte CA, Cowman MK. Determination of hyaluronan molecular mass distribution in human breast milk. Anal Biochem (2015) 474:78-88. doi:10.1016/j.ab.2014.12.020

38. Balazs EA, Sundblad L. Viscosity of hyaluronic acid solutions containing proteins. Acta Soc Med Ups (1959) 64:137-46.

39. Tengblad A. Quantitative analysis of hyaluronate in nanogram amounts. Biochem J (1980) 185:101-5.

40. Engström-Laurent A, Laurent UBG, Lilja K, Laurent TC. Concentration of sodium hyaluronate in serum. Scand J Clin Lab Invest (1985) 45:497-504. doi: $10.3109 / 00365518509155249$

41. Fosang AJ, Hey NJ, Carney SL, Hardingham TE. An ELISA plate based assay for hyaluronan using biotinylated proteoglycan G1 domain (HA-binding region). Matrix (1990) 10:306-13. doi:10.1016/S0934-8832(11)80186-1

42. Haserodt S, Aytekin M, Dweik RA. A comparison of the sensitivity, specificity and molecular weight accuracy the three different commercially available hyaluronan ELISA-like assays. Glycobiology (2011) 21:175-83. doi:10.1093/ glycob/cwq145

43. Yuan H, Tank M, Alsofyani A, Shah N, Talati N, LoBello JC, et al. Molecular mass dependence of hyaluronan detection by sandwich ELISA-like assay and membrane blotting using biotinylated HA binding protein. Glycobiology (2013) 23:1270-80. doi:10.1093/glycob/cwt064

44. Laurent UBG, Tengblad A. Determination of hyaluronate in biological samples by a specific radioassay technique. Anal Biochem (1980) 109:386-94. doi:10. 1016/0003-2697(80)90665-X

45. Bogdani M, Simeonovic C, Nagy N, Johnson PY, Chan CK, Wight TN. The detection of glycosaminoglycans in pancreatic islets and lymphoid tissues. Methods Mol Biol (2015) 1229:413-30. doi:10.1007/978-1-4939-1714-3_32

46. Lindqvist U, Chichibu K, Delpech B, Goldberg RL, Knudson W, Poole AR, et al. Seven different assays of hyaluronan compared for clinical utility. Clin Chem (1992) 38:127-32.

47. Jadin L, Huang L, Wei G, Zhao Q, Gelb AB, Frost GI, et al. Characterization of a novel recombinant hyaluronan binding protein for tissue hyaluronan detection. J Histochem Cytochem (2014) 62:672-83. doi:10.1369/0022155414540176

48. Balazs EA, Watson D, Duff IF, Roseman S. Hyaluronic acid in synovial fluid: I. Molecular parameters of hyaluronic acid in normal and arthritis human fluids. Arthritis Rheum (1967) 10:357-76. doi:10.1002/art.1780100407

49. Balazs EA. Viscoelastic properties of hyaluronic acid and biological lubrication. Univ Mich Med Cent J (1968):255-9.

50. Dahl LB, Dahl IMS, Engstrom-Laurent A, Granath K. Concentration and molecular weight of sodium hyaluronate in synovial fluid from patients with rheumatoid arthritis and other arthropathies. Ann Rheum Dis (1985) 44:817-22. doi:10.1136/ard.44.12.817

51. Österlin S. On the molecular biology of the vitreous in the aphakic eye. Acta Ophthalmol (1977) 55:353-61. doi:10.1111/j.1755-3768.1977.tb06109.x

52. Laurent UBG. Hyaluronate in aqueous humour. Exp Eye Res (1981) 33:147-55. doi:10.1016/S0014-4835(81)80063-2

53. Holmes MWA, Bayliss MT, Muir H. Hyaluronic acid in human articular cartilage. Age-related changes in content and size. Biochem J (1988) 250: 435-41.

54. Tammi R, Ågren UM, Tuhkanen A-L, Tammi M. Hyaluronan metabolism in skin. Prog Histochem Cytochem (1994) 29:1-81. doi:10.1016/S0079-6336(11) 80023-9

55. Crawford DHG, Murphy TL, Ramm LE, Fletcher LM, Clouston AD, Anderson GJ, et al. Serum hyaluronic acid with serum ferritin accurately predicts cirrhosis and reduces the need for liver biopsy in C282Y hemochromatosis. Hepatology (2009) 49:418-25. doi:10.1002/hep.22650

56. Sasaki Y, Uzuki M, Nohmi K, Kitagawa H, Kamataki A, Komagamine M, et al. Quantitative measurement of serum hyaluronic acid molecular weight in rheumatoid arthritis patients and the role of hyaluronidases. Int J Rheum Dis (2011) 14:313-9. doi:10.1111/j.1756-185X.2011.01683.x

57. Grigoreas GH, Anagnostides ST, Vynios DH. A solid-phase assay for the quantitative analysis of hyaluronic acid at the nanogram level. Anal Biochem (2003) 320:179-84. doi:10.1016/S0003-2697(03)00386-5

58. Kongtawelert P, Ghosh P. A method for the quantitation of hyaluronan (hyaluronic acid) in biological fluids using a labeled avidin-biotin technique. Anal Biochem (1990) 185:313-8. doi:10.1016/0003-2697(90)90300-X
59. Delpech B, Bertrand P, Maingonnat C. Immunoenzymoassay of the hyaluronic acid - hyaluronectin interaction: application to the detection of hyaluronic acid in serum of normal subjects and cancer patients. Anal Biochem (1985) 149:555-65. doi:10.1016/0003-2697(85)90613-X

60. Dahl IMS, Laurent TC. Concentration of hyaluronan in the serum of untreated cancer patients with special reference to patients with mesothelioma. Cancer (1988) 62:326-30. doi:10.1002/1097-0142(19880715)62:2<326:: AID-CNCR2820620217>3.0.CO;2-Y

61. Yahya RS, El-Bindary AA, El-Mezayen HA, Abdelmasseh HM, Eissa MA. Biochemical evaluation of hyaluronic acid in breast cancer. Clin Lab (2014) 60:1115-21. doi:10.7754/Clin.Lab.2013.130413

62. Wu M, Cao M, He Y, Liu Y, Yang C, Du Y, et al. A novel role of low molecular weight hyaluronan in breast cancer metastasis. FASEB J (2015) 29:1290-8. doi:10.1096/fj.14-259978

63. Takeuchi J, Sobue M, Sato E, Shamoto M, Miura K, Nakagaki S. Variation in glycosaminoglycan components of breast tumors. Cancer Res (1976) 36:2133-9.

64. Olsen EB, Trier K, Eldov K, Ammitzbøll T. Glycosaminoglycans in human breast cancer. Acta Obstet Gynecol Scand (1988) 67:539-42. doi:10.3109/ 00016348809029866

65. Li XQ, Thonar EJ-MA, Knudson W. Accumulation of hyaluronate in human lung carcinoma as measured by a new hyaluronate ELISA. Connect Tissue Res (1989) 19:243-53. doi:10.3109/03008208909043899

66. Hiltunen ELJ, Anttila M, Kultti A, Ropponen K, Penttinen J, Yliskoski M, et al. Elevated hyaluronan concentration without hyaluronidase activation in malignant epithelial ovarian tumors. Cancer Res (2002) 62:6410-3.

67. Lokeshwar VB, Rubiniwicz D, Schroeder GL, Forgacs E, Minna JD, Block NL, et al. Stromal and epithelial expression of tumor markers hyaluronic acid and HYAL1 hyaluronidase in prostate cancer. J Biol Chem (2001) 276:11922-32. doi:10.1074/jbc.M008432200

68. Auvinen P, Tammi R, Kosma V-M, Sironen R, Soini Y, Mannermaa A. Increased hyaluronan content and stromal cell CD44 associate with HER2 positivity and poor prognosis in human breast cancer. Int J Cancer (2013) 132:531-9. doi:10.1002/ijc. 27707

69. Tainen S, Tumelius R, Rilla K, Hämäläinen K, Tammi M, Tammi R, et al. High numbers of macrophages, especially M2-like (CD163-positive), correlate with hyaluronan accumulation and poor outcome in breast cancer. Histopathology (2015) 66(6):873-83. doi:10.1111/his.12607

70. Schwertfeger K, Cowman MK, Telmer P, Turley E, McCarthy JB. Hyaluronan, inflammation and breast cancer progression. Front Immunol (2015) 6:236. doi:10.3389/fimmu.2015.00236

71. Tammi R, Pasonen-Seppånen S, Kolehmainen E, Tammi M. Hyaluronan synthase induction and hyaluronan accumulation in mouse epidermis following skin injury. J Invest Dermatol (2005) 124:898-905. doi:10.1111/j.0022-202X. 2005.23697.x

72. Neudecker BA, Stern R, Connollly MK. Aberrant serum hyaluronan and hyaluronidase levels in scleroderma. Br J Dermatol (2004) 150:469-76. doi:10. 1046/j.1365-2133.2004.05805.x

73. Bollyky PL, Bogdani M, Bollyky JB, Hull RL, Wight TN. The role of hyaluronan and the extracellular matrix in islet inflammation and immune regulation. Curr Diab Rep (2012) 12:471-80. doi:10.1007/s11892-012-0297-0

74. Rauhala L, Hämäläinen L, Salonen P, Bart G, Tammi M, Pasonen-Seppänen S, et al. Low dose ultraviolet $B$ irradiation increases hyaluronan synthesis in epidermal keratinocytes via sequential induction of hyaluronan synthases Has1-3 mediated by $\mathrm{p} 38$ and Ca2+/calmodulin-dependent protein kinase II (CaMKII) signaling. J Biol Chem (2013) 288:17999-8012. doi:10.1074/jbc.M113.472530

75. Kwiecinski JJ, Dorosz SG, Hill TE, Abubacker S, Cowman MK, Schmidt TA. The effect of molecular weight on hyaluronan's cartilage boundary lubricating ability - alone and in combination with proteoglycan 4. Osteoarthritis Cartilage (2011) 19:1356-62. doi:10.1016/j.joca.2011.07.019

76. Baggenstoss BA, Weigel PH. Size exclusion chromatography-multiangle laser light scattering analysis of hyaluronan size distributions made by membranebound hyaluronan synthase. Anal Biochem (2006) 352:243-51. doi:10.1016/j. ab.2006.01.019

77. Cowman MK, Mendichi R. Methods for determination of hyaluronan molecular weight. In: Garg HG, Hales CA, editors. Chemistry and Biology of Hyaluronan. Amsterdam: Elsevier Press (2004). p. 41-69.

78. Hayase S, Oda Y, Honda S, Kakehi K. High-performance capillary electrophoresis of hyaluronic acid: determination of its amount and molecular mass. J Chromatogr A (1997) 768:295-305. doi:10.1016/S0021-9673(96)01095-3 
79. Mahoney DJ, Aplin RT, Calabro A, Hascall VC, Day AJ. Novel methods for the preparation and characterization of hyaluronan oligosaccharides of defined length. Glycobiology (2001) 11:1025-33. doi:10.1093/glycob/11.12.1025

80. Volpi N. On-line HPLC/ESI-MS separation and characterization of hyaluronan oligosaccharides from 2-mers to 40-mers. Anal Chem (2007) 79:6390-7. doi:10. 1021/ac070837d

81. Malm L, Hellman U, Larsson G. Size determination of hyaluronan using a gasphase electrophoretic mobility molecular analysis. Glycobiology (2012) 22:7-11. doi:10.1093/glycob/cwr096

82. Laurent UBG, Granath KA. The molecular weight of hyaluronate in the aqueous humour and vitreous body of rabbit and cattle eyes. Exp Eye Res (1983) 36:481-91. doi:10.1016/0014-4835(83)90042-8

83. Min H, Cowman M. Combined alcian blue and silver staining of glycosaminoglycans in polyacrylamide gels: application to electrophoretic analysis of molecular weight distribution. Anal Biochem (1986) 155:275-85. doi:10.1016/ 0003-2697(86)90437-9

84. Lee HG, Cowman MK. An agarose gel electrophoretic method for analysis of hyaluronan molecular weight distribution. Anal Biochem (1994) 219:278-87. doi:10.1006/abio.1994.1267

85. Bhilocha S, Amin R, Pandya M, Yuan H, Tank M, LoBello J, et al. Agarose and polyacrylamide gel electrophoresis methods for molecular weight analysis of 5-500 kDa HA. Anal Biochem (2011) 417:41-9. doi:10.1016/j.ab. 2011.05.026

86. Cowman MK, Chen CC, Pandya M, Yuan H, Ramkishun D, LoBello J, et al. Improved agarose gel electrophoresis method and molecular weight calculation for high molecular weight hyaluronan. Anal Biochem (2011) 417:50-6. doi:10. 1016/j.ab.2011.05.023

87. Balazs EA, Gibbs DA. The rheological properties and biological function of hyaluronic acid. In: Balazs EA, editor. Chemistry and Molecular Biology of the Intercellular Matrix. New York, NY: Academic Press (1970). p. 1241-54.

88. Balazs EA. The physical properties of synovial fluid and the special role of hyaluronic acid. 2nd ed. In: Helfet A, editor. Disorders of the Knee. Philadelphia, PA: JB Lippincott Company (1982). p. 61-74.

89. Balazs EA, Denlinger JL. Sodium hyaluronate and joint function. J Equine Vet Sci (1985) 5:217-28. doi:10.1016/S0737-0806(85)80102-7

90. Lee HG. An Agarose Gel Electrophoretic Method for Hyaluronan Molecular Weight Analysis and its Application to Osteoarthritic Synovial Hyaluronan. [Ph.D. Dissertation], Polytechnic University (1994) Available through ProQuest LLC, Ann Arbor, MI.
91. Bjelle A, Andersson T, Granath K. Molecular weight distribution of hyaluronic acid of human synovial fluid in rheumatic diseases. Scand J Rheumatol (1982) 12:133-8. doi:10.3109/03009748309102899

92. Dahl LB, Dahl IM, Borresen AL. The molecular weight of sodium hyaluronate in amniotic fluid. Biochem Med Metab Biol (1986) 35:219-26. doi:10.1016/ 0885-4505(86)90077-0

93. Armstrong SE, Bell DR. Relationship between lymph and tissue hyaluronan in skin and skeletal muscle. Am J Physiol Heart Circ Physiol (2002) 283:H2485-94. doi:10.1152/ajpheart.00385.2002

94. Lokeshwar VB, Öbek C, Soloway MS, Block NL. Tumor-associated hyaluronic acid: a new sensitive and specific urine marker for bladder cancer. Cancer Res (1997) 57:773-7.

95. Franzmann EJ, Schroeder GL, Goodwin WJ, Weed DT, Fisher P, Lokeshwar VB. Expression of tumor markers hyaluronic acid and hyaluronidases (Hyal1) in head and neck tumors. Int J Cancer (2003) 106:438-45. doi:10.1002/ijc.11252

96. Kumar S, West DC, Ponting JM, Gattamaneni HR. Sera of children with renal tumours contain low-molecular-mass hyaluronic acid. Int J Cancer (1989) 44:445-8. doi:10.1002/ijc.2910440311

97. Tian X, Azpurua J, Hine C, Vaidya A, Myakishev-Rempel M, Ablaeva J, et al. High-molecular-mass hyaluronan mediates the cancer resistance of the naked mole rat. Nature (2013) 499:346-9. doi:10.1038/nature12234

98. Ruscheinsky M, de la Motte CA, Mahendroo M. Hyaluronan and its binding proteins during cervical ripening and parturition: dynamic changes in size, distribution and temporal sequence. Matrix Biol (2008) 27:487-97. doi:10.1016/ j.matbio.2008.01.010

99. Declèves A-E, Caron N, Voisin V, Legrand A, Bouby N, Kultti A, et al. Synthesis and fragmentation of hyaluronan in renal ischaemia. Nephrol Dial Transplant (2012) 27:3771-81. doi:10.1093/ndt/gfs098

Conflict of Interest Statement: The authors declare that the research was conducted in the absence of any commercial or financial relationships that could be construed as a potential conflict of interest.

Copyright (C) 2015 Cowman, Lee, Schwertfeger, McCarthy and Turley. This is an openaccess article distributed under the terms of the Creative Commons Attribution License (CC BY). The use, distribution or reproduction in other forums is permitted, provided the original author(s) or licensor are credited and that the original publication in this journal is cited, in accordance with accepted academic practice. No use, distribution or reproduction is permitted which does not comply with these terms. 